An integrative and socio-cultural perspective of health, wealth, and adjustment in widowhood

Dr Michelle DiGiacomo BA, MHSc(Hons), PhD (Corresponding Author)

Centre for Cardiovascular and Chronic Care

School of Nursing, Midwifery and Health

University of Technology Sydney and Curtin University

PO Box 123

Broadway New South Wales 2007 Australia

Telephone +6129514 4819

Email michelle.digiacomo@uts.edu.au

Professor Patricia M. Davidson RN, BA, MEd, PhD

Centre for Cardiovascular and Chronic Care

School of Nursing, Midwifery and Health

University of Technology Sydney

PO Box 123

Broadway New South Wales 2007 Australia

Email patriciamary.davidson@uts.edu.au

Professor Julie Byles BMed, PhD

Research Centre for Gender, Health and Ageing

Faculty of Health

University of Newcastle

Associate Professor Marie T. Nolan RN, MPH, PhD

School of Nursing

Johns Hopkins University

Baltimore, MD, USA 


\section{An integrative and socio-cultural perspective of health, wealth, and adjustment in widowhood}

Women comprise a larger proportion of the ageing population, often outlive their spouses, and face a variety of challenges upon widowhood. Discrete aspects of the health impact of widowhood have been described in the literature; however, the expanse of socio-contextual issues that impact on older women's adjustment is less prominent. We undertook a literature review to synthesize recent research and interventions and identify current trends and gaps in knowledge and services. Although many health, social, cultural, economic factors impact on recently widowed older women throughout the world, we found few interventions targeting this population incorporating these factors.

The proportion of women in ageing populations throughout the world is larger than men because they commonly outlive their male spouses (United Nations Department of Economic and Social Affairs [UN DESA], 2010). The death of a spouse propels an individual into a new life phase, often without preparation, guidelines, or accompaniment and requires adjustment to personal and social changes, often during a period of debilitating grief (Holmes \& Rahe, 1967). Widowhood is not just a passing stage of grief, bereavement, and adjustment, but instead represents another developmental phase in which women can expect to live for an average of 15 years (Australian Bureau of Statistics [ABS], 2007). Although men also experience spousal bereavement, a gendered approach recognizes that roles of men and women are dynamic and socially-defined constructs with unique internal and external expectations and vulnerabilities, shaped by social, economic, political and cultural factors, rather than just biology (Williams, Baker, Allman, \& Roseman, 2006).

Whereas men have been found to be more at risk of death in the years following spousal bereavement (Bowling, 1994), older women are more prone to disability and financial insecurity upon widowhood and are described as more disadvantaged compared to older men (UN DESA, 2010; Lee, 2003). Studies have reported that women are particularly at risk for a range of chronic 
health conditions and economic deprivation, particularly upon spousal bereavement (Williams et al., 2006). Women survive their husbands and often there is no planning for when this happens (Lee, 2003). Widows are vulnerable to lower standards of living, poor health outcomes, isolation, and decreased quality of life, lack of advocacy, and premature death. In life transitions, providing appropriate, timely and effective services is of critical importance (Davidson, Dracup, Phillips, Padilla, \& Daly, 2007), yet there are few services directed towards these women. Previous reviews of the literature on widowhood have mainly been approached using biological and/or psychological frameworks to discuss health risks and outcomes (Clark \& Caffarella, 1999; Stroebe, Schut, \& Stroebe, 2007). However, a complex interplay of physical, psychological, social, economic, cultural and political issues impact on women's overall wellbeing and adjustment to widowhood and these may differ by age group. Further, the perspective of gender on roles and societal perceptions are also important to consider. Recognizing these factors is important in considering interventions to help women cope and adjust during this period of vulnerability. Appreciating the experience of widowhood within an integrative framework incorporating a sociocultural context is of critical importance (Asian-Pacific Resource \& Research Centre for Women [ARROW], 1999; Davidson, DiGiacomo, \& McGrath, 2010).

\section{Methodology}

We reviewed recent literature on widowhood within an integrative framework that recognizes the intersection and influence of biological, psychological, and sociocultural frames (Clark \& Caffarella, 1999). In March 2012, articles were searched via Expanded Academic ASAP, PsychInfo, Medline, Cumulative Index to Nursing and Allied Health Literature (CINAHL), for the period of $1990-2012$ using the search terms 'widow*', 'spousal bereavement', 'women', and 'intervention'. Reference lists of obtained articles were hand-searched. Articles were included if they were written in English and depicted issues associated with widowhood in women aged 50 and over. Where articles 
contained information depicting both women and men, the findings related to women were incorporated. We approached in consideration of the reciprocal and interactive framework between women's experiences of their partners' death and bereavement and their personal internal resources and networks as well as social, political and economic factors. Titles and abstracts were assessed for relevance independently by two reviewers. Data were extracted from primary sources and tabled. A general inductive approach (Thomas, 2006) was used to ascertain categories reflecting broad themes depicted within the literature. The literature reflecting these themes was summarized and conclusions and suggestions for future research discussed.

\section{Results}

We identified 62 peer-reviewed journal articles relevant to widowhood in older women for inclusion in this review. This literature was comprised predominantly of articles centring on health outcomes, factors affecting outcomes, and interventions for the recently bereaved. The following is a summary of reported outcomes and associated factors followed by a detailed synopsis of interventions aimed to address these issues.

\section{Health Outcomes}

Although ageing is associated with an increase in chronic health conditions, for some, the experience of widowhood adds an additional level of vulnerability to physical and mental health problems and death. The first two years of widowhood, hereafter referred to as recent widowhood, can be a critical period where a variety of health issues arise (Laditka \& Laditka, 2003). Strobe et al.'s (2007) recent review of the health outcomes of bereavement concluded that an early excess health risk in studies predominantly focusing on older women, are attributable to psychological distress, loneliness, changes in social ties, living arrangements, eating habits, and economic support. In addition, the recently bereaved are more likely to have physical health problems, have a disability, 
be hospitalised, and use medications compared to their non-bereaved counterparts (Stroebe et al., 2007).

Other studies report an increased incidence of poor psychological health, including depression, anxiety, and loneliness (Onrust \& Cuijpers, 2006; Williams, 2005) and a greater decline in memory (Aartsen, Van Tilburg, Smits, Comijs, \& Knipscheer, 2005). The United States (US) National Institute of Mental Health (NIMH) (1999) found that one-third of widows studied met the criteria for clinical depression in the first month after spousal death, and half of these remained clinically depressed a year later. This trend is disconcerting given the known associations between psychological states and physical health. For instance, a mental health index score that is within the clinical range has been found to be an independent risk factor for new diagnosis of diabetes in elderly women (NIMH, 1999). Bereavement and depression both tend to increase cardiovascular mortality rates (Strodl \& Kenardy, 2006). Increased psychological stress in conjunction with changed behaviours and an altered physiological state, may trigger cardiovascular events, especially in those most at risk (Buckley, McKinley, Tofler, \& Bartrop, 2010; Tofler \& Muller, 2006). Furthermore, older widowed persons are at risk of suicide in the short- and medium-term following spousal death (Ajdacic-Gross et al., 2008).

Declines in self-care, including those associated with daily activities as well as health care utilisation, can be influenced by recent conjugal loss and this can impact on health outcomes. The spouse may have served as the recipient or co-performer of certain mutually beneficial behaviors, be they related to household management or self-care. Wilcox et al. (2003) found unintentional weight loss to be a physical health consequence found in recently widowed ( $<12$ months) women. Where wives previously may have been the meal preparer for the couple, the absence of another person within the household may limit the same degree of effort in obtaining nourishment. In the early days following the loss and even as new patterns emerge, eating habits often change. Widows eat more meals alone or skip meals, prepare food less often and eat more pre-prepared foods, have less 
variety in dietary intake and lose interest in meal planning, shopping, and meal preparation (Quandt, McDonald, Arcury, Bell, \& Vitolins, 2000; Shahar, Schultz, Shahar, \& Wing, 2001). As a result of these changed behaviors, nutritional status declines which contributes to ill-health and death (Rauscher, 1993). Furthermore, widows may receive fewer health reminders, guidelines, and instruction which may have previously been a function of their spouse (Williams, 2004).

Exercise during early bereavement is associated with better self-rated health, physical functioning, and greater energy (Young, Dobson, \& Byles, 2000) twelve months post-loss (Chen, Gill, \& Prigerson, 2005) in older adults. However, newly bereaved women may reduce their physical activity for reasons associated with reduced perception of health, a decreased social network, and financial cost, and the lack of a partner to participate with (Grimby, Johansson, Sundh, \& Grimby, 2008; Patterson \& Chang, 1999). Widowhood has been associated with inferior exercise adherence in middle-aged adults and decreased adherence to class-based physical activity (Oman \& King, 2000).

During period of caregiving and acute bereavement, women can be distracted from addressing their own health care needs (Jin \& Chrisatakis, 2009); a finding that may relate to the increased health care utilization throughout bereavement. Recently widowed older women were reported to have a 40 percent higher risk of hospitalization than their non-recently widowed counterparts (Laditka \& Laditka, 2003). In fact, widows reported higher health care utilization than non-widows and taking prescribed medicines, in part for mental health reasons (Avis, Brambilla, Vass, \& McKinlay, 1991). Byles, Feldman and Mishra (1999) found that recently bereaved women were more likely to be taking medication for 'nerves' (18 percent) or sleep-inducing medications ( 25 percent) than women widowed longer.

Although older women are more likely than older men to use the services of a general practitioner (Australian Institute of Health and Welfare [AIHW], 2007), Feldman, Byles, and Beaumont (2000) found that widows' support needs were broader than those relating to physical health and were not necessarily met by medical professionals. Recent widows needed understanding, support, and 
information from medical practitioners (Feldman et al., 2000), however, further detail regarding these needs or the characteristics of the relationship between widows and their health care professionals are not known. Poor physical and psychological health outcomes highlight the need for health professionals to be aware of and responsive to issues faced by older women who have recently lost a spouse (Williams, 2005).

\section{Factors affecting outcomes}

Despite this long list of vulnerabilities and negative health outcomes, research indicated that people are generally resilient and recover over time (Boerner, Wortman, \& Bonanno, 2005). The ways in which people respond to bereavement are mediated by a range of well-researched risk and protective factors at individual, community, and societal levels (Stroebe et al., 2007). In this review, we identified that prominent factors affecting outcomes in older widowed women were economic resources, living arrangements, and social support and participation.

\section{Economic Resources}

Among older couples, income often dies with a spouse (Rosenman, 2000). Changes in many developed countries, including the increasing chasm between the rich and poor (Duckett, 2005), and the lessening ability of people with lower incomes to access health care services (Young et al., 2000), mean that the loss of a spouse and his financial resources can be linked with not only declines in economic and physical and mental wellbeing of widows (Burkhauser, Butler, \& Holden, 1991), but also their health. Angel, Jimenez, and Angel (2007) found a substantial economic decline for older widows, particularly those from minority groups. Older widows are three times as likely to live in poverty as older married people (McGarry \& Schoeni, 2005). Seventy-five percent of older poor individuals are women and they are twice as likely to live in poverty as men (Smeeding, 1999). Up to 56 percent of the difference in economic status between widows and married older individuals is due to the death of the spouse, including loss of income and expenses associated with dying. On 
average, out of pocket medical expenses in the final two years of life were equal to 30 percent of the couple's annual income and much higher for those with lower incomes (McGarry \& Schoeni, 2005). This loss of income, expenses associated with dying, and higher health-care expenses during bereavement (Genevro, Marshall, \& Miller, 2004) combine to put women in often unmanageable financial situations while contributing to psycho-emotional strain during this grief period. For example, in Australia, government-funded pensions and income from compulsory retirement savings and investments are the main sources of income for most retired older people, yet half of women born between 1946 and 1961 have retirement savings accounts of $\$ 8,000$ or less (Kelly, 2006). In light of this, some countries have supported a public policy emphasis to encourage older workers to remain longer in paid employment. Average income in households with a reference person aged 65 years and over is lower than the national average (ABS, 2007), yet living costs are increasing for this population (AIHW, 2007). These older women face rapid declines in pension income three months following their husband's death when payments previously designated to support two people are reduced by almost half for a single person. This swift and marked decrease can force women to adapt to new living arrangements and environments. Widows of veterans may be able to receive some income support and housing and funeral assistance from relevant veteran's organizations or government departments. However, many older women do not qualify for such support.

Similar economic sequelae for older widowed women were reported in other countries. In the USA and Germany, decreases in social security and pension income have been found to be the greatest contributor to drops in living standards for older widows, thereby highlighting the inadequacies in retirement income systems for widows (Hungerford, 2001). A study in Hong Kong found that women were less likely to have engaged in financial planning for retirement, making them prime candidates for poverty given increases in longevity (Lee, 2003). Researchers from Sweden found that unequal pre-death income resulted in increased psycho-social and economic difficulties for widows. They concluded that a gendered labour market characterised by unequal intra-household income distribution has an impact on the coping process following spousal death. 


\section{Living Arrangements}

The death of a husband may lead to a change in living arrangements for the widow due to financial necessity, health status, preference to live with family, or other reasons. Recent widows reported being stressed housing and financial management (Byles et al., 1999) and reported anxiety and depression about financial and housing insecurity (Feldman et al., 2000). While living with others may provide relief from financial pressure (Dodge, 1995), it may also contribute to higher levels of depression and poorer functioning (Gustavson \& Lee, 2004). Alternatively, widows may prefer to live alone and retain their independence (Johnson, Barer, \& Gullickson, 1997). For some women, it is the first time they have ever lived alone. The proportion of older people living alone increases with age and it is associated with a higher likelihood of poverty (Dodge, 1995). A recent study by McFarran (2010) on older women was prompted by evidence of increasing numbers of older women entering the homeless population. The study argued for a gendered analysis of housing, homelessness and ageing policy in order to understand and respond to the different experiences of women and men (McFarren, 2010). In 2003, in Australia, 35 percent of older women and 60 percent of women aged 85 and over lived alone and this rate is projected to increase (ABS, 2006). Older women living alone can lack the social support and additional informal home care often critical to chronic disease management (Estes \& Michel, 1999), are at risk of experiencing loneliness and social isolation, and are more likely to need outside assistance in the case of illness.

The need to feel safe and secure is also an issue when living alone and can contribute to quality of life in older people. Women over age 65 have been found to feel more vulnerable when home alone at night than men, and women even older report feeling unsafe at home alone even during the day (AlHW, 2007). Furthermore, self- and home care represent areas where more women than men aged 65 years and over require assistance (ABS, 2004). Areas of greatest difference between men's and women's need for assistance were property maintenance (35 percent of women and 21 percent of men), housework ( 26 percent of women and 14 percent of men) and transport (26 percent of 
women and 17 percent of men). Government-funded Community Aged Care Programs may provide home-based care, such as provision of personal care, domestic assistance, social support, assistance with meal preparation and other food services, respite care, rehabilitation support, home maintenance, delivered meals, linen services and transport for frail or disabled older people living in the community. In Australia, over 59 percent of all package recipients are women aged 75 years and over. Questions remain, however, concerning accessibility of such services and whether geography or functional status limits access.

\section{Social Support and Participation}

The role of social support in women's experiences of widowhood has been widely studied. Laditka and Laditka's (2003) finding that socially isolated widows had a considerably higher risk of hospitalization than those in contact with friends and family underscores the mediating effect of social connectedness on the health of recently bereaved older women. In this study, social connectedness, as measured by having had phone contact with a friend/neighbour/family member in the period prior to the baseline survey, significantly decreased hospitalization risk for recently bereaved older women. Risk of entering long-term institutional care after death of spouse is particularly high immediately after death, demonstrating importance of social and instrumental support (Nihtila \& Martikainen, 2008). Timing of this apparent protective factor was assessed in Guiaux, Van Tilburg and Broese Van Groenou's (2007) study which found that contact and support increased in all relationships after widowhood, particularly in child and sibling relationships, although it diminished after approximately 2.5 years.

Other recent studies have focused on describing the perceptions and experiences of social support from the perspectives of widows. In a mixed-method study, Scott et al. (2007) explored new widows' meanings and experiences of social support. Following the death, family support was reported as both instrumental and emotional. Instrumental support included offering money, 
helping with chores and maintenance, serving as liaisons, and being available as needs arose. Neighbors checked in on widows and anticipated needs by doing things prior to being asked. Families provided emotional support after deaths through their company, check-in phone calls, and affection. Widowed friends and relatives were supportive through their company, advice, normalizing, and their example.

Children were described as a major source of support, thus childless older people have been found to have lower level of support (Gray, 2009). Upon widowhood, however, older adults with children rely on a broader range of relationships rather than just family and close friends. Existing support networks were preferred over formal bereavement groups (Scott et al., 2007). Activity-based networks such as card clubs and church organizations were relied on for support (Guiaux et al., 2007). In a UK study, informal social networks facilitated social support in the lives of older people rather than civic involvement, particularly in the working class (Gray, 2009). Only involvement in sports and religious clubs were found to provide supportive friendships (Gray, 2009). Rather than withdrawing for social participation, Feldman et al. (2002) found that most women maintained or increased their level of social contact and participation in activities since becoming widowed. Volunteer roles adopted after spousal loss have been found to protect against depressive symptoms and enhance self-efficacy (Li, 2007).

A key to many of these informal groups is the mutual aid interaction wherein widows support each other rather than one person being targeted for receiving support (Scott et al., 2007). Within a mutual aid model, the sharing of experiences and advice contributes to feelings of empowerment and self-esteem. A study by Brown, Nesse, Vinokur and Smith (2003) found decreased rates of mortality in individuals providing instrumental support to family, friends, and neighbors, whereas receiving support had no effect on mortality, suggesting that giving support may be more important than receiving it. In her study describing the social capital of older people, Gray (2009) defined this constructs as an individual resource developed through a person's activities and contingent on 
others' attitudes. She discovered that ill health can lessen one's ability to reciprocate or help others and can impact negatively on social support and social capital.

Neighbourhoods and communities featured as important venues for social capital building and social support. Gray (2009) found high levels of support in people who lived in friendly neighbourhoods. Findings of a study on neighborhood composition suggested that living amongst other widows can provide interaction opportunities and promotion of new social engagements, thereby improving longevity (Subramanian, Elwert, \& Christakis, 2008). In addition, Rosenbaum (2006) found that restaurants, coffee shops, and other similar businesses are serving as places for emotional and social support to people who may otherwise be lonely.

Despite its widely reported benefits, Scott et al. (2007) further reveal that social support was a complex and nuanced construct wherein satisfaction with support fluctuated, often on a daily basis for some women, there was a mismatch between needed and available support, and widows feared loss of support if overused. These findings indicate that social support is not a one-size-fits-all construct, but rather, it varied according to individual and situational differences.

Miller, Smerglia and Bouchet (2004) conducted a review of studies to examine the effect of social support on women's adjustment to widowhood. Findings revealed no effect on adjustment and no clear evidence of whether socio-emotional or instrumental support was more helpful in women's adjustment to widowhood (Miller et al., 2004). Although widows may feel closer to family, friends and neighbors as a result of social support, their adjustment was hindered by financial or healthrelated concerns. Furthermore, when adjustment occurs, it may be due to something other than social support. The major determinants of adjustment in the studies analyzed often were variables such as health/health problems, years widowed, income, religious involvement, or limitations/functional ability. 
Although not specifically targeting older women, Stroebe et al.'s (2007) review of psychological counseling and therapy interventions of bereaved individuals ultimately supported the tenet that not all bereaved people benefit from such interventions; however, individuals with higher levels of mental-health problems and complicated grief show better outcomes (Parkes, 1998). When offered to all bereaved people, regardless of risk or complication status, just $20 \%$ of studies $(n=4)$ reported positive outcomes. Three of these (75\%) were participant-initiated involvement in the intervention as opposed participants not having a choice of whether they would engage in counselling.

A systematic review of bereavement interventions that pre-dated publication parameters of the current review was identified (Potocky, 1993). This systematic review concluded that individual and group modalities were effective, yet programs identified did not reflect ecological approaches to practice, instead focusing on individuals' psychological processes and experiences in isolation from the larger environment. For example, these studies predominantly did not incorporate external or environmental strains, such as financial hardship, into intervention assessment. Authors of this review suggested that future research and practice with bereaved individuals and services should address a variety of factors in the person-environment perspective (Potocky, 1993).

A small number of other intervention studies, not characterised as psychological therapy and predominantly targeting older women, were identified $(n=5)$. Four of these interventions were delivered in face-to-face group format and one described a one-to-one intervention with health professionals. Two of the studies assessed the more traditional support group, mutual aid, self-help style programs. Two of the studies utilized peer facilitators as delivery personnel while the other three were facilitated by health professionals. Group programs were undertaken in weekly sessions over 5-20 weeks for 1-2 hours. Interventions were located at community venues. Four of the interventions included both men and women aged 50 and older, yet these did not report outcomes for women separately. Outcomes measured via questionnaire included quality of life, self-esteem, 
anxiety, psychosomatic symptoms, life satisfaction, affect, loneliness/isolation, depression, grief, support need, self-efficacy in self-care, level of understanding of grief issues, and application of learned skills.

Two of these interventions were randomised control trials (RCTs) of support groups. Lund and colleagues (2010) tested efficacy of a support program guided by the Dual Process Model (DPM) of coping whereby one group centred on topics association with loss orientation (LO) and the other included both loss and restoration orientation (RO) (DPM group). There was no difference found between groups, however participant feedback indicated the need to tailoring sequencing and content of bereavement interventions according to individuals' need (Lund et al., 2010). Lund et al. (2010) posited that participants' high satisfaction with the interventions may reflect natural benefits of group intervention, opportunities to speak and hear from others about the loss of a spouse or life partner.

Caserta and Lund (1993) compared effects of a short-term traditional support group (8 weekly selfhelp group meetings) with a long-term (12-month (consisting of 8 weekly self-help group meetings +10 monthly meetings), and a no-intervention group. Results indicated that the intervention did not appear to directly impact depression and interpersonal resources were more influential than selfhelp groups.

In another study by this team, a structured health education and self-care program aimed to provide education on health and wellbeing in a supportive environment where participants could develop self-care and daily living skills and learn how to access additional community resources to meet their needs. Results showed improved self-efficacy in exercise, accessing community resources, organising and maintaining the home, and cooking. Other results were statistically significant yet incremental increases in active coping, health care participation, household management, home 
safety, and nutritional self-care skills. Further, nearly $70 \%$ of participants sought additional information from sources outside the classes. The authors concluded that bereavement interventions that address other issues in addition to grief and loss issues are a promising model (Caserta, Lund, \& Obray, 2004; Caserta, Lund, \& Rice, 1999).

Following a self-help support group where participants were encouraged to inform content and direction of the program, support needs were diminished and positive affect increased. There was also a trend toward decreased social isolation and emotional loneliness. In post-intervention semistructured interviews, bereaved seniors reported increased hope, improved skills in developing social relationships, enhanced coping, new role identities, and less loneliness (Stewart, Craig, MacPherson, \& Alexander, 2001).

Although not specifically targeting widows or widowers, a systematic review was identified that focused on health promotion interventions that target social isolation and loneliness among community-dwelling older people. The authors concluded that educational and social activity group interventions that target specific groups can alleviate social isolation and loneliness among older people, yet effectiveness of home visiting and befriending schemes remained unclear (Cattan, White, Bond, \& Learmouth, 2005).

\section{Discussion}

Widowhood has a broad impact on the lives of women with extensive, social, political and economic implications. In this review, we identified that studies describing health outcomes both physical and psychological, dominate the peer-reviewed literature in widowhood in older women. Although the majority of women demonstrate resilience and adjust to these changed circumstances over time (Wilcox et al., 2003), a minority is at higher risk of adverse events, therefore identifying these women and addressing their needs is of utmost importance. In particular, findings regarding unmet 
needs in health professional interactions signal the importance of health professionals being aware of and responsive to issues faced by older women and to appreciate individual differences.

Economic sequelae influenced by gender are pertinent issues relevant to ageing populations throughout the world. These issues may challenge living arrangements and self-management, thus perpetuating vulnerability.

Older widowed women, particularly those without children, rely on a broader range of support, hence the importance of maintaining contact with formal and informal networks, particularly those that include younger people. Thuen, Reime and Strautvoll (1997) argue that both widows and widowers have lower levels of social support than married individuals (Stewart et al., 2001). A related construct, social capital, or productive benefits of social relationships, has been found to influence the relationship between neighbourhood and community characteristics and psychosocial wellbeing, health behaviours and healthcare access (Lindström, 2008). In particular, social capital can act as a buffer to chronic health problems, and socioeconomic and environmental decline (Rogers, Huxley, Evans, \& Gately, 2008). Despite having strong networks, however, a woman's health is an important factor in her ability to engage within these networks and to develop social capital.

The minimal number of intervention studies which address strategies for assisting women to cope and adjust to their changed situations is a concerning deficit. Given the importance of broader social networks in adjustment of recently bereaved older women, development of programs to assist women to acquire new skills, access affordable and reliable sources of support for necessities such as home maintenance, and to ensure high levels of social support and interaction with peers and community are required (Byles \& Feldman, 2006). We identified few interventions targeting older recently bereaved women and most of these included men as well. Key elements of effective interventions included (Cattan \& White, 1998; Findlay, 2003):

- Group-based activities (discussion, bereavement support, self-help) 
- Targeting specific groups (e.g. women, widows)

- Including older people in development, implementation, evaluation of programs

- Incorporating a variety of strategies that can be tailored to suit individual needs

- Providing training and support for facilitators

- Using existing community resources and build community capacity

Despite isolation or loneliness, it is important to appreciate that not all older recently bereaved women want to participate in such programs for a range of physical and psychological health reasons (Findlay, 2003). This review underscores the complexity of widowhood and the need to consider these factors within not only a gendered framework, but also a sociological context. Future research and practice should incorporate socio-ecological approaches that takes into account social structure, policy, and systems; community; institutional/organizational; and interpersonal spheres of influence (McLeroy, Bibeau, Steckler, \& Glanz, 1988). Research and services targeting overall adjustment and other environmental issues that are not traditionally the primary concern of psychologists or bereavement interventions may interest and benefit those experiencing normal grief. Where possible, strategies that reduce or eliminate the causes of isolation or loneliness and build protective factors, such as social capital through neighbourhood and community enrichment, and incorporating younger people into programs with older generations. There are inherent dangers in viewing widowhood as an adversity rather than a life transition, but equally failing to acknowledge the impact this has on women may condemn women to loneliness, poverty, and adverse health outcomes. 


\section{References}

Aartsen, M. J., Van Tilburg, T., Smits, C. H. M., Comijs, H. C., \& Knipscheer, K. C. P. M. (2005). Does widowhood affect memory performance of older persons? Psychological Medicine, 35(2), 217-226.

Ajdacic-Gross, V., Ring, M., Gadola, E., Lauber, C., Bopp, M., Gutzwiller, F., et al. (2008). Suicide after bereavement: an overlooked problem. Psychological Medicine, 38(5), 673-676.

Angel, J., Jimenez, M., \& Angel, R. (2007). The economic consequences of widowhood for older minority women. [Comparative Study]. Gerontologist, 47(2), 224-234.

Asian-Pacific Resource \& Research Centre for Women (ARROW). (1999). Feminisation of ageing in Asia-Pacific: health implications. Arrows for Change.

Australian Bureau of Statistics. (2004). Disability, Ageing, and Carers: Summary of Findings: ABS. Australian Bureau of Statistics. (2006). Health of Older People in Australia: A Snapshot, 2004-05: ABS. Australian Bureau of Statistics. (2007). Lifetime Marriage and Divorce Trends: ABS.

Australian Institute of Health and Welfare. (2007). Older Australia at a Glance, 4th edition: Australian Institute of Health and Welfare.

Avis, N., Brambilla, D., Vass, K., \& McKinlay, J. (1991). The effect of widowhood on health: a prospective analysis from the Massachusetts Women's Health Study. Social Science \& Medicine, 33(9), 1063-1070.

Boerner, K., Wortman, C., \& Bonanno, G. (2005). Resilient or at risk? A 4-year study of older adults who initially showed high or low distress following conjugal loss. Journal of Gerontology, $60 B(2), 67-73$.

Bowling, A. (1994). Mortality after bereavement: an analysis of mortality rates and associations with mortality 13 years after bereavement. International Journal Geriatric Psychiatry, 9, 445-459.

Brown, S., Nesse, R., Vinokur, A., \& Smith, D. (2003). Providing social support may be more beneficial than receiving it: results from a prospective study. Psychological Science, 14(4), 320-327. 
Buckley, T., McKinley, S., Tofler, G., \& Bartrop, R. (2010). Cardiovascular risk in early bereavement: A literature review and proposed mechanisms. International Journal of Nursing Studies, 47(2), 229-238.

Burkhauser, R. V., Butler, J. S., \& Holden, K. C. (1991). How the death of a spouse affects economic well-being after retirement: A hazard model approach. Social Science Quarterly, 72(3), 504519.

Byles, J., \& Feldman, S. (2006). The lives of older widowed women. Just Policy, 39, 23-25.

Byles, J., Feldman, S., \& Mishra, G. (1999). For richer, for poorer, in sickness and in health: older widowed women's health, relationships and financial security. Women \& Health, 29(1), 1530.

Caserta, M., \& Lund, D. (1993). Intrapersonal resources and the effectiveness of self-help groups for bereaved older adults. The Gerontologist, 33(5), 619.

Caserta, M., Lund, D., \& Obray, S. (2004). Promoting self-care and daily living skills among older widows and widowers: evidence from the Pathfinders demonstration project. Omega: Journal of Death \& Dying, 49(3), 217-236.

Caserta, M., Lund, D., \& Rice, S. (1999). Pathfinders: A self-care and health education program for older widows and widowers. The Gerontologist, 39(5), 615.

Cattan, M., \& White, M. (1998). Developing evidence based health promotion for older people: A systematic review and survey of health promotion interventions targeting social isolation and loneliness among older people. Internet Journal of Health Promotion, 13, 1-9.

Cattan, M., White, M., Bond, J., \& Learmouth, A. (2005). Preventing social isolation and loneliness among older people: a systematic review of health promotion interventions. Ageing \& Society, 25, 41-67.

Chen, J. H., Gill, T. M., \& Prigerson, H. G. (2005). Health behaviors associated with better quality of life for older bereaved persons. Journal of Palliative Medicine, 8(1), 96-106. 
Clark, M. C., \& Caffarella, R. S. (1999). Theorizing Adult Development. New Directions for Adult and Continuing Education, 84, 3-8.

Davidson, P., DiGiacomo, M., \& McGrath, S. (2010). The feminisation of ageing: how will this impact on health outcomes and services? Health Care for Women International, 32(12), 1031-1045. Davidson, P., Dracup, K., Phillips, J., Padilla, G., \& Daly, J. (2007). Maintaining Hope in Transition: A Theoretical Framework to Guide Interventions for People With Heart Failure. Journal of Cardiovascular Nursing, 22(1), 58-64.

Department of Economic and Social Affairs. (2010). World Population Ageing 2009: United Nations. Dodge, H. (1995). Movements out of poverty among elderly widows. Journals of Gerontology Series B-Psychological Sciences \& Social Sciences, 50(4), S240-249.

Duckett, S. J. (2005). Living in the parallel universe in Australia: public Medicare and private hospitals. CMAJ Canadian Medical Association Journal, 173(7), 745-747.

Estes, C. L., \& Michel, M. (1999). Social Security and Women. In The America Task Force on Women (Ed.), Social Security in the 21st Century. Gerontological Society of America.

Feldman, S., Byles, J., Mishra, G., \& Powers, J. (2002). The health and social needs of recently widowed older women in Australia. Australasian Journal of Ageing, 21, 135-140.

Feldman, S., Byles, J. E., \& Beaumont, R. (2000). 'Is anybody listening?' The experiences of widowhood for older Australian women. Journal of Women \& Aging, 12(3/4), 155-176.

Findlay, R. (2003). Interventions to reduce social isolation amongst older people: Where is the evidence? Ageing and Society, 23, 647.

Genevro, J. L., Marshall, T., \& Miller, T. (2004). Report on bereavement and grief research. Death Studies, 28(6), 491-575.

Gray, A. (2009). The social capital of older people. Ageing \& Society, 29(01), 5-31.

Grimby, A., Johansson, A., Sundh, V., \& Grimby, G. (2008). Walking habits in elderly widows. American Journal of Hospice \& Palliative Medicine, 25(2), 81-87. 
Guiaux, M., Van Tilburg, T., \& Broese Van Groenou, M. (2007). Changes in contact and support exchange in personal networks after widowhood. Personal Relationships, 14(3), 457-473.

Gustavson, K., \& Lee, C. D. (2004). Alone and content: frail seniors living in their own home compared to those who live with others. Journal of Women \& Aging, 16(3/4), 3-18.

Holmes, T., \& Rahe, R. (1967). The social readjustment rating scale. Journal of Psychosomatic Research, 11(2), 213-218.

Hungerford, T. (2001). The economic consequences of widowhood on elderly women in the United States and Germany. Gerontologist, 41(1), 103-110.

Jin, L., \& Chrisatakis, N. (2009). Investigating the mechanism of marital mortality reduction: The transition to widowhood and quality of health care. Demography, 46(3), 605-625.

Johnson, C. L., Barer, B. M., \& Gullickson, T. (1997). Life Beyond 85 Years: The Aura of Survivorship. PsycCRITIQUES, 42(11), 1043.

Kelly, S. (2006). Mapping behavioural trends of the baby boomers. Canberra: National Centre for Social and Economic Modelling.

Laditka, J. N., \& Laditka, S. B. (2003). Increased hospitalization risk for recently widowed older women and protective effects of social contacts. Journal of Women \& Aging, 15(2/3), 7-28.

Lee, W. K. M. (2003). Women and Retirement Planning: Towards the "Feminization of Poverty" in an Aging Hong Kong. Journal of Women \& Aging, 15(1), 31-53.

Li, Y. (2007). Recovering from spousal bereavement in later life: does volunteer participation play a role? Journals of Gerontology Series B-Psychological Sciences \& Social Sciences, 62(4), 257266.

Lindström, M. (2008). Social Capital and Health-Related Behaviors. In I. Kawachi, S. V. Subramanian \& D. Kim (Eds.), Social Capital and Health (pp. 215-238). New York: Springer.

Lund, D., Caserta, M., Utz, R., \& De Vries, B. (2010). Experiences and early coping of bereaved spouses/partners in an intervention based on the dual process model (dpm). Omega, 61(4), 291-313. 
McFarren, L. (2010). It Could Be You: Female, Single, Older and Homeless. Sydney, Australia: Homelessness NSW, Older Women's Network NSW \& St Vincent de Paul Society.

McGarry, K., \& Schoeni, R. F. (2005). Widow(er) poverty and out-of-pocket medical expenditures near the end of life. Journals of Gerontology, 60B(3), S160-168.

McLeroy, K., Bibeau, D., Steckler, A., \& Glanz, K. (1988). An ecological perspective on health promotion programs. Health Educ Quarterly, 15, 351-377.

Miller, N., Smerglia, V., \& Bouchet, N. (2004). Women's adjustment to widowhood: does social support matter? Journal of Women and Aging, 16(3/4), 149-167.

National Institute of Mental Health. (1999). The Many Dimensions of Depression in Women: Women at Risk.

Nihtila, E., \& Martikainen, P. (2008). Institutionalization of older adults after the death of a spouse. American Journal of Public Health, 98(7), 1228-1234.

Oman, R. F., \& King, A. C. (2000). The effect of life events and exercise program format on the adoption and maintenance of exercise behavior. Health Psychology, 19(6), 605-612.

Onrust, S. A., \& Cuijpers, P. (2006). Mood and anxiety disorders in widowhood: a systematic review. Aging \& Mental Health, 10(4), 327-334.

Parkes, C. (1998). Coping with loss: consequences and implications for care. International Journal of Palliative Nursing, 5(5), 250-254.

Patterson, I., \& Chang, M. (1999). Participation in Physical Activities by Older Australians: a Review of the Social Psychological Benefits and Constraints. Australasian Journal on Ageing, 18(4), 179185.

Potocky, M. (1993). Effective services for bereaved spouses: a content analysis of the empirical literature. Health \& Social Work, 18(4).

Quandt, S. A., McDonald, J., Arcury, T. A., Bell, R. A., \& Vitolins, M. Z. (2000). Nutritional selfmanagement of elderly widows in rural communities. Gerontologist, 40(1), 86-96. 
Rauscher, C. (1993). Malnutrition among the elderly. [Review]. Canadian Family Physician, 39, 13951403.

Rogers, A., Huxley, P., Evans, S., \& Gately, C. (2008). More than jobs and houses: mental health, quality of life and the perceptions of locality in an area undergoing urban regeneration. Social Psychiatry and Psychiatric Epidemiology, 43(5), 364-372.

Rosenbaum, M. S. (2006). Exploring the Social Supportive Role of Third Places in Consumers' Lives Journal of Service Research, 9, 59-72.

Rosenman, L. (2000). Is widowhood out of date in the 21st century? Paper presented at the International Research Conference on Social Security, Helsinki, Finland.

Scott, S., Bergman, C. S., Verney, A., Longenbaker, S., Markey, M., \& Bisconti, T. (2007). Social support in widowhood. Journal of Mixed Methods Research, 1(3), 242-266.

Shahar, D. R., Schultz, R., Shahar, A., \& Wing, R. R. (2001). The effect of widowhood on weight change, dietary intake, and eating behavior in the elderly population. Journal of Aging \& Health, 13(2), 186-199.

Smeeding, T. M. (1999). Social Security Reform: Improving Benefit Adequacy and Economic Security for Women. Syracuse, NY: Syracuse University.

Stewart, M., Craig, D., MacPherson, K., \& Alexander, S. (2001). Promoting positive affect and diminishing loneliness of widowed seniors through a support intervention. Public Health Nursing, 18(1), 54-63.

Strodl, E., \& Kenardy, J. (2006). Psychosocial and non-psychosocial risk factors for the new diagnosis of diabetes in elderly women. Diabetes Research and Clinical Practice, 74(1), 57-65.

Stroebe, M., Schut, H., \& Stroebe, W. (2007). Health outcomes of bereavement. The Lancet, 370(9603), 1960-1973.

Subramanian, S. V., Elwert, F., \& Christakis, N. (2008). Widowhood and mortality among the elderly: the modifying role of neighborhood concentration of widowed individuals. Social Science \& Medicine, 66(4), 873-884. 
Thomas, D. (2006). A general inductive approach for qualitative data analysis. American Journal of Evaluation, 27(2), 237-246.

Thuen, F., Reime, M., \& Skrautvoll, K. (1997). Received social support from informal networks and professionals in bereavement. Psychology, Health and Medicine, 2(1), 51-63.

Tofler, G., \& Muller, J. (2006). Triggering of acute cardiovascular disease and potential preventive strategies. Circulation, 114, 1863-1872.

Wilcox, S., Evenson, K. R., Aragaki, A., Wassertheil-Smoller, S., Mouton, C. P., \& Loevinger, B. L. (2003). The effects of widowhood on physical and mental health, health behaviors, and health outcomes: the women's health initiative. Health Psychology, 22(5), 513-522.

Williams, B., Baker, P., Allman, R., \& Roseman, J. (2006). The feminization of bereavement among community-dwelling older adults. [Research Support, N.I.H., Extramural]. Journal of Women \& Aging, 18(3), 3-18.

Williams, J. (2005). Depression as a Mediator between Spousal Bereavement and Mortality from Cardiovascular Disease: Appreciating and Managing the Adverse Health Consequences of Depression in an Elderly Surviving Spouse. Southern Medical Journal, 98, 90-95.

Williams, K. (2004). The transition to widowhood and the social regulation of health: consequences for health and health risk behavior. Journals of Gerontology Series B: Psychological Sciences \& Social Sciences, 59B(6), S343-349.

Young, A., Dobson, A., \& Byles, J. (2000). Access and equity in the provision of general practitioner services for women in Australia. Australian \& New Zealand Journal of Public Health, 24(5), 474-480. 